\title{
Comparative analysis of the nuclear lens opalescence by the Lens Opacities Classification System III with nuclear density values provided by Oculus Pentacam: a cross-section study using Pentacam Nucleus Staging software
}

\author{
Análise comparativa da opalencência nuclear cristaliniana pelo Lens Opacities Classification System III \\ com valores de densidade nuclear fornecidos pelo Oculus Pentacam: estudo transversal utilizando o \\ Pentacam Nucleus Staging software
}

Fernanda Pedreira Magalhães ${ }^{1}$, Elaine Fiod Costa $^{1}$, Angelino Júlio Cariello ${ }^{1}$, Eduardo Buchele Rodrigues ${ }^{1}$, Ana Luisa Hofling-Lima ${ }^{1}$

\begin{abstract}
Purpose: To compare the clinical classification of cataract using the Lens Opacities Classification System (LOCS) III with the mean values of lens density provided by the Pentacam Scheimpflug System in nuclear cataracts.

Methods: One hundred and one eyes from 101 patients with age-related nuclear cataract were submitted to clinical examination for lens grading score using LOCS III. According to LOCS III, nuclear opalescence was divided in six groups. Patients were evaluated by the Pentacam Scheimpflug System for the mean lens density using the Pentacam lens densitometry program (PLDP), the Pentacam Nucleus Staging (PNS) mean value and the PNS cataract grading score.

Results: A positive correlation between the mean values of lens density and LOCS III classification, considering groups 1 to 5, could be noticed with PLDP and PNS mean value. The mean values between the groups were similar using the PLDP and the PNS mean value. However, when the PNS cataract grading score was evaluated, there was low correspondence with LOCS III classification.

Conclusion: Pentacam Scheimpflug device offers an objective measure of the lens nuclear density on nuclear cataracts. PLDP and the PNS mean value were both usefu to evaluate age-related nuclear cataract up to LOCS III group 5.
\end{abstract}

Keywords: Cataract/classification; Densitometry/methods; Lens nucleus, crystalline; Cross-sectional studies

\section{RESUMO}

Objetivo: Comparar a classificação clínica de catarata nuclear, utilizando o Lens Opacities Classification System (LOCS) III, e o valores médios de densidade nuclear fornecido pelo sistema Pentacam Sheimpflug.

Métodos: Cento e um pacientes (101 olhos) com diagnóstico de catarata nuclear senil foram submetidos a exame clínico para graduação da opalescência nuclear de acordo com o LOCS III e divididos em seis grupos de acordo com a mesma. Os pacientes foram posteriormente avaliados pelo sistema Pentacam Scheimpflug para obtenção do valor médio de densidade fornecido pelo programa de densitometria cristaliniana do aparelho (PLDP), valor médio de densidade calculado pelo Pentacam Nucleus Staging software (PNS) e o escore de graduação de catarata nuclear fornecido pelo PNS.

Resultados: Observou-se uma correlação positiva entre os valores médios de densidade cristaliniana fornecidos pelo PLDP e PNS e a classificação clínica LOCS III, considerando os grupos 1 ao 5. Os valores médios de densidade nuclear de cada grupo foram similares utilizando dados do PLDP e PNS. Entretanto, quando foi analisado o escore de graduação da catarata fornecido pelo PNS foi observada uma baixa correspondência com a classificação LOCSIII.

Conclusão: O Pentacam Scheimpflug oferece uma medida objetiva da densidade nuclear cristaliniana em cataratas nucleares. Os valores médios de densidade nuclear fornecidos pelo PLDP e PNS foram úteis na avaliação de catarata nuclear senil até o grupo 5 da classificação LOCS III.

Descritores: Catarata/classificação; Densitometria/métodos; Núcleo do cristalino; Estudos transversais

\section{INTRODUCTION}

Age-related cataract is a highly prevalent disease and the leading cause of reversible blindness in the world ${ }^{(1-2)}$. In the past four decades, age-related cataract has been widely studied both in terms of natural history and treatment. Nevertheless, there has been a continued interest in developing reliable methods of measuring lens transparency and cataract growth. Classification systems have been created in order to characterize the different stages of cataract, to guide surgical planning and to standardize cataract related studies $^{(3)}$.
Currently, the most commonly used clinical method to classify cataract is The Lens Opacities Classification System III (LOCS III). The method was validated in 1993 based on slit-lamp and retroillumination images ${ }^{(4-5)}$. The LOCS III comes with detailed instructions about its correct use showing photographic images of the cataract grade scale that can be applied to grade cataracts on a real-time slitlamp ${ }^{(5)}$. Aside from being important to grade the type and severity of cataract in many cross-section and population studies ${ }^{(3)}$, the LOCS III is also important in clinical practice specially considering public healthy care systems, where a low cost classification method

Submitted for publication: December 22, 2010

Accepted for publication: January 31,2011

Study carried out at the Departamento de Oftalmologia, Universidade Federal de São Paulo UNIFESP.

Physician, Department of Ophthalmology, Universidade Federal de São Paulo - UNIFESP - São Paulo (SP), Brazil.

Funding: No specific financial support was available for this study.

Disclosure of potential conflicts of interest: F.P.Magalhães, None; E.F.Costa, None; A.J.Cariello, None; E.B.Rodrigues, None; A. L. Höfling-Lima, None.

Correspondence address: Fernanda Pedreira Magalhães. Department of Ophthalmology, Federal University of São Paulo. Rua Botucatu, 820 - São Paulo - SP - 04023-062 - Brazil

E-mail: fernandapedreiramagalhaes@yahoo.com.br 
is required ${ }^{(5)}$. However, the LOCS III method is susceptible to a variety of interpretations, according to different observers, which might compromise its reproducibility ${ }^{(5)}$.

Nowadays, new optical technologies such as the Pentacam imaging device (Oculus Inc., Wetzlar, Germany) have been developed to offer objective images of the anterior chamber structures including lens density evaluation ${ }^{(6)}$. Pentacam imaging is a noncontact device, which uses a rotating Scheimpflug camera to capture the images $^{(7)}$. The measuring process takes 2 seconds to perform 12 to 50 single captures, the pictures are detected and processed to a 3dimensional model of the anterior eye segment ${ }^{(8)}$. It provides anterior and posterior corneal topography ${ }^{(9)}$, complete corneal pachymetry ${ }^{(7)}, 3$-dimension chamber analysis (depth, angle and volume) ${ }^{(8)}$ and the lens density ${ }^{(10)}$.

The lens density can be measured with the traditional software that comes with the Pentacam device ${ }^{(10)}$ and using the new software Pentacam Nucleus Staging (PNS). The PNS gives information about the mean density value, the standard deviation and the maximum of nuclear density. The software likewise measures a three-dimensional template volume and optical density that generate a nuclear cataract grade in five stages (PNS cataract grading score). Nevertheless, this nuclear cataract classification is not based only on the densitometry values, but also on formulas not revealed by the manufacturer.

The purpose of this study was to compare the results of nuclear opalescence clinical classification using LOCS III to the mean values of lens density provided by the Pentacam and its new software PNS, in nuclear cataracts, in order to establish a direct correlation between a subjective and objective method.

\section{METHODS}

One hundred and one eyes of 101 patients were enrolled into this cross-sectional study performed in the Cataract Service at the Federal University of São Paulo, Brazil. The study was approved by the Human Research Ethics Committee/Investigational Review Board of the Federal University of São Paulo (Ethical committee protocol number 1634/06) and adhered to the guidelines of the Declaration of Helsinki. Written informed consent was obtained from all participants.

Cataract grading was performed using the LOCS III scale during a Cataract Campaign. A single, properly trained ophthalmologist was asked to grade the patient's nuclear cataract and examined all the patients under pupil dilatation (two drops of 1\% tropicamide). The patients were then separated into six groups according to their nuclear opalescence. Patients included had mainly nuclear cataract, patients with cortical or subcapsular opacities were excluded. Exclusion criteria were the history of corneal injury, corneal opacities, abnormalities of the eye anterior segment, physical disabilities, previous ocular surgery and no age-related cataracts.
Group 1 included nuclear opalescence graduated between 1.0 to 1.9; group 2 included nuclear opalescence graduated between 2.0 to 2.9; group 3 included nuclear opalescence graduated between 3.0 to 3.9; group 4 included nuclear opalescence graduated between 4.0 to 4.9; group 5 included nuclear opalescence graduated between 5.0 to 5.9, and group 6 included nuclear opalescence graduated between 6.0 to 6.9 .

Oculus Pentacam (Oculus Inc., Germany) images were scheduled for a week later after the clinical examination. The Oculus Pentacam images were obtained under pupil dilatation with $1 \%$ tropicamide. All images were obtained at the same room for all patients with a consistent environment in each screening using the same device, after the equipments calibration. The patient was seated with his or her chin on a chinrest and forehead against the forehead strap and asked to fixate ahead on a target. The operator visualized a real-time image of the patient's eye on a computer screen, with the machine marking the pupil edge and center manually focus and aligns the image. To reduce operator-dependent variables, Pentacam's automatic release mode was used. In this mode, the instrument automatically determines when correct focus and alignment with the corneal apex have been achieved and then performs a scan. In less than 2 seconds, the rotating camera captures up to 50 slit images of the anterior segment.

The Pentacam Scheimpflug densitometric method, with the blue light-scattering intensity of the lens layers numerically graded, was used to measure the nuclear density. On the three-dimensional plot of the anterior segment with each section running through the corneal vertex, the required lens density was taken as the mean value on the image at 45 degrees in both eyes, using the traditional lens density assessment function available in the Pentacam software (Pentacam lens density program - PLDP) and the PNS. In cases which the image at 45 degrees could not be obtained, the image with better lens visualization was selected. The mean area analyzed by the PNS, measuring $1.60 \mathrm{~mm}^{2}$, was placed in the nucleus and the threshold value considered was 20\%. The average nuclear density and the nuclear cataract classification were recorded. The results between the data obtained with PLDP, PNS mean value and PNS cataract grading score were compared with LOCS III classification (Figure 1).

Data were collected and compared among the six groups. The mean difference and standard deviation (SD) were calculated. KruskalWallis test was used to compare the PLDP mean nuclear density according to each group, and, posteriorly, Mann-Whitney test was performed to compare groups two by two. The $p$-values of Mann-Whitney test were corrected for multiple comparisons using Bonferroni adjustment.

The ANOVA model was used to compare groups 1 to 6 with respect to the average nuclear density measured by PNS. The p-values for comparison of groups two by two were also corrected for multiple comparisons using the Bonferroni adjustment.

Spearman correlations coefficients were calculated between PLDP and PNS mean values for all the groups. A $p$ value $<0.05$ was considered statistically significant.
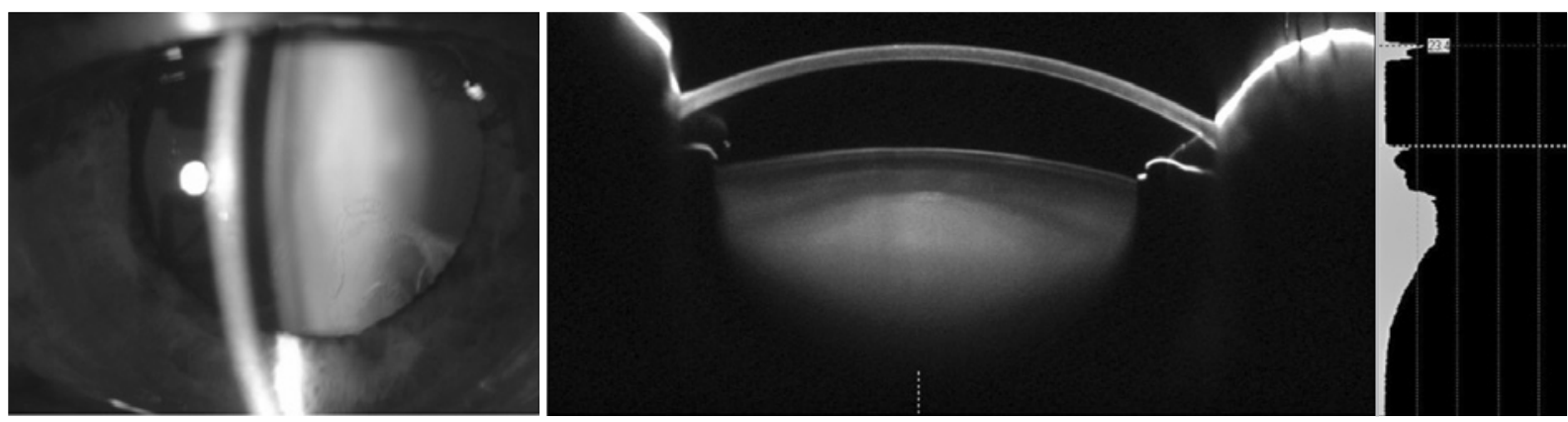

Figure 1. The image of a group 5 nuclear cataract (LOCS III), on the left; lens density evaluation, by Pentacam Scheimpflug system, on the right. 


\section{RESULTS}

This study comprised 101 eyes from 101 patients (47 males and 54 females) diagnosed as having age-related nuclear cataract. The age ranged from 39 to 88 years, with mean age of 68 . The average number of eyes included in each group was 16.83 .

Considering the PLDP, a positive correlation could be noticed between the mean values of lens density and LOCS III classification considering groups 1 to 5 . Further, the mean value of lens density in the group 6 was lower than in the group 5, despite the higher median value found. The standard deviation of the lens density mean value increased among groups 5 and 6, and the maximum value of density was found in the group 5 (Table 1). Evaluating the statistical analysis about the difference in the mean lens density measurement between the groups, this difference occured between group 1 to 3, 4, 5 and 6, group 2 to 4, 5 and 6, and group 3 to 4, 5 and 6 (Table 2).

The PNS mean value software also demonstrated a correlation between the average of nuclear lens density and LOCS III grading considering groups 1 to 5 . The group 6 , thought, presented a value of lens density lower than the value of group 3 (Table 3 ). The PNS was not able to evaluate the lens density in 8 eyes of group 6, even when different scans other than 45 degrees were examined. Using this software, the only group that the mean value was statistically different from all the rest was group 5, statistical difference was also found between groups 1 and 4 (Table 4).

Considering the nuclear cataract grade in five stages informed by the PNS, there was a great variability of these values among the six groups (Table 5). Most of the patients included in the LOCS III groups 1, 2, 3 and 4 were classified by the PNS software as stage 1. Additionally, the majority of the patients in group 5 (70.6\%) were disposed in stage 2 or 3 . Furthermore, $47.1 \%$ of the patients located in group 6 could not be graded by the software.

Table 1. Lens density measurement using PLDP according to LOCS III group classification

\begin{tabular}{lccccc}
\hline Group & Mean & SD & Minimum & Median & Maximum \\
\hline 1 & 10.09 & 1.42 & 7.86 & 9.92 & 13.02 \\
2 & 11.29 & 1.81 & 8.62 & 11.20 & 14.34 \\
3 & 11.85 & 0.93 & 10.04 & 11.96 & 13.34 \\
4 & 14.14 & 2.64 & 9.38 & 14.72 & 18.22 \\
5 & 18.12 & 6.18 & 13.54 & 16.86 & 40.58 \\
6 & 17.73 & 4.91 & 12.12 & 17.32 & 29.52 \\
\hline
\end{tabular}

$\mathrm{SD}=$ standard deviation

Table 2. Groups comparisons two by two (PLDP mean value)

\begin{tabular}{|c|c|}
\hline Comparisons & p-value \\
\hline Group 1 X Group 2 & $1.000 *$ \\
\hline Group 1 X Group 3 & $0.006^{*}$ \\
\hline Group 1 X Group 4 & $<0.001^{*}$ \\
\hline Group 1 X Group 5 & $<0.001^{*}$ \\
\hline Group 1 X Group 6 & $<0.001^{*}$ \\
\hline Group 2 X Group 3 & $1.000^{*}$ \\
\hline Group 2 X Group 4 & $0.022^{*}$ \\
\hline Group 2 X Group 5 & $<0.001^{*}$ \\
\hline Group 2 X Group 6 & $<0.001^{*}$ \\
\hline Group 3 X Group 4 & $0.048^{*}$ \\
\hline Group 3 X Group 5 & $<0.001^{*}$ \\
\hline Group 3 X Group 6 & $<0.001^{*}$ \\
\hline Group 4 X Group 5 & $0.071^{*}$ \\
\hline Group 4 X Group 6 & $0.606^{*}$ \\
\hline Group 5 X Group 6 & $1.000^{*}$ \\
\hline
\end{tabular}

${ }^{*} \mathrm{p}$-value for the nonparametric Mann-Whitney test corrected by Bonferroni
Comparing PLDP and PNS mean values, positive Spearman correlation coefficients were found for all six groups, considering $p$ value $<0.05$, with a higher correlation in groups 1,2 and 4 , a moderate correlation in group 3, and reasonable correlation in group 6. All associations were statistically significant, except for group 6 (Table 6).

\section{DISCUSSION}

LOCS III is well recognized as an age-related cataract grading scheme and is widely used for clinical and research study ${ }^{(11)}$. However, it has limitations rooted in observer bias and questions concerning interobserver and intraobserver reliability ${ }^{(12)}$. It is important, thought, to have an objective method to evaluate and quantify lens opacities. Pentacam (Oculus) offers an objective evaluation of the entire anterior eye segment, including lens densitometry, in a single scan without contact with the cornea ${ }^{(12)}$. Considering its ability to evaluate the lens density, this present study compared the findings of Scheimpflug densitometry of the human lens nucleus, considering the mean value, with the clinical classification LOCS III of agerelated nuclear cataracts.

Results of this study showed an increasing correlation between lens density and LOCS III nuclear opalescence score among groups 1 to 5 using the PLDP and PNS mean value, and a positive correlation coefficient between both techniques. Considering the PLDP, statistical differences between all consecutive groups were not found, suggesting that a change in grade of LOCS III classification may not necessary mean a significant increase in the nuclear density. Group 6 also showed lower mean values than group 5, probably because the density was so high in this group that did not allow light to pass through the lens nuclei, interfering in the lens density measures.

Similar results were found using the PNS software, with which the mean value of nuclear density in group 6 was lower than in

Table 3. Lens density measurement using the PNS mean value according to LOCS III group classification

\begin{tabular}{lccccc}
\hline Group & Mean & SD & Minimum & Median & Maximum \\
\hline 1 & 10.49 & 1.76 & 7.50 & 10.50 & 14.90 \\
2 & 12.48 & 2.69 & 8.90 & 12.25 & 17.80 \\
3 & 14.76 & 3.46 & 11.60 & 13.90 & 23.40 \\
4 & 15.91 & 4.12 & 10.80 & 15.80 & 25.60 \\
5 & 20.88 & 7.76 & 14.60 & 18.40 & 47.80 \\
6 & 13.12 & 1.66 & 10.50 & 13.00 & 15.60 \\
\hline
\end{tabular}

$\mathrm{SD}=$ standard deviation

Table 4. Groups comparisons two by two (PNS mean value)

\begin{tabular}{lr}
\hline Comparisons & p-value \\
\hline Group 1 X Group 2 & $1.000^{* *}$ \\
Group 1 X Group 3 & $0.138^{* *}$ \\
Group 1 X Group 4 & $0.016^{* *}$ \\
Group 1 X Group 5 & $<0.001^{* *}$ \\
Group 1 X Group 6 & $1.000^{* *}$ \\
Group 2 X Group 3 & $0.724^{* *}$ \\
Group 2 X Group 4 & $0.115^{* *}$ \\
Group 2 X Group 5 & $<0.001^{* *}$ \\
Group 2 X Group 6 & $1.000^{* *}$ \\
Group 3 X Group 4 & $1.000^{* *}$ \\
Group 3 X Group 5 & $0.002^{* *}$ \\
Group 3 X Group 6 & $1.000^{* *}$ \\
Group 4 X Group 5 & $0.029^{* *}$ \\
Group 4 X Group 6 & $1.000^{* *}$ \\
Group 5 X Group 6 & $0.001^{* *}$ \\
\hline
\end{tabular}

**p-value of ANOVA model corrected by Bonferroni 
Table 5. PNS cataract grading score: groups descriptive analysis

\begin{tabular}{lll}
\hline PNS cataract grading score values & $\mathbf{n}$ & $\mathbf{( \% )}$ \\
\hline Group 1 & 3 & $(18.8 \%)$ \\
0 & 8 & $(50.0 \%)$ \\
1 & 4 & $(25.0 \%)$ \\
2 & 1 & $(6.3 \%)$ \\
3 & & \\
Group 2 & 11 & $(64.7 \%)$ \\
1 & 5 & $(29.4 \%)$ \\
2 & 1 & $(5.9 \%)$ \\
NA & & \\
Group 3 & 7 & $(41.2 \%)$ \\
1 & 7 & $(41.2 \%)$ \\
2 & 2 & $(11.8 \%)$ \\
3 & 1 & $(5.9 \%)$ \\
4 & & $(41.2 \%)$ \\
Group 4 & 7 & $(23.5 \%)$ \\
1 & 7 & $(29.4 \%)$ \\
2 & 4 & $(5.9 \%)$ \\
3 & 5 & $(35.3 \%)$ \\
4 & 1 & $(35.3 \%)$ \\
Group 5 & & $(11.8 \%)$ \\
2 & & $(17.6 \%)$ \\
3 & 6 & $(29.4 \%)$ \\
4 & 6 & $(11.8 \%)$ \\
5 & 2 & $(11.8 \%)$ \\
Group 6 & 3 & \\
1 & $3.1 \%)$ \\
2 & & \\
3 & 5 & \\
NA & 2 & \\
\hline
\end{tabular}

$N A=$ not applicable (device was not able to analyze data)

Table 6. Spearman correlation coefficient between each group considering PLDP and PNS mean value

\begin{tabular}{lcc}
\hline Comparisons & Correlation coefficient & (p-value) \\
\hline PLDP group 1 X PNS group 1 & 0.891 & $(<0.001)$ \\
PLDP group 2 X PNS group 2 & 0.763 & $(0.006)$ \\
PLDP group 3 X PNS group 3 & 0.495 & $(0.043)$ \\
PLDP group 4 X PNS group 4 & 0.819 & $(0.001)$ \\
PLDP group 5 X PNS group 5 & 0.570 & $(0.017)$ \\
PLDP group 6 X PNS group 6 & 0.350 & $(0.356)$ \\
\hline
\end{tabular}

groups 3, 4 and 5. The PNS was also unable to analyze the lens density in 8 eyes of group 6 . The PNS cataract grading score did not show any consistent correlation compared with the clinical grading by LOCS III. In clinical practice, the mean value of nuclear density provided by the PNS should be more reliable to evaluate the progression of early nuclear opacification rather than the cataract score informed by the software. Although, both scores provided by this new device still need to be validated with further studies.

Pei et al. ${ }^{(10)}$ investigated the relationship between lens density measured with the Pentacam Scheimpflug System and grading score using LOCS III in 138 cases (180 eyes). They found a linear increasing correlation between the peak value of lens density measured with the Pentacam and the grading score using the LOCS III system in nuclear cataract patients, including the group 6 of this classification. The peak value of lens evaluates just one point of the lens density and may not represent the entire nucleus. This study, though, did not use the peak value but the mean value of lens density, which can justify the difference in terms of results.

Datiles et al. ${ }^{(13)}$ also used the Scheimpflug method to detect changes in the nuclear region of the lens over a one year period. Twenty five eyes with pure nuclear cataract were evaluated with LOCS II and the Scheimpflug method; the second one proved to be more sensitive in detecting lens changes than the clinical method, since lens density could present nuclear change earlier than LOCS II. These results suggest that the Scheimpflug system may be an important device in evaluating cataract development, especially in clinical studies.

Although Pentacam evaluation of the lens densitometry is a good objective method, it has some disadvantages as it gives the absolute density values and may be affected by external factors, such as corneal opacities, insufficient pupil dilatation, changes in photographic illumination, film processing, and different image analysts, even with standardization of the gray scale. Color Scheimpflug photographs have been used by Sasaki et al..$^{(14)}$ to analyze aging changes in the human lens and in the study of lens color in vivo; densitometry was performed using three color filters-red, green, and blue. They showed that changes in the anterior half of the lens nucleus is better imaged in the blue wavelength, whereas the posterior half is better imaged in the red wavelength. The Pentacam Scheimpflug camera uses mainly the blue light scan which may interfere in the density measurement and may not be as accurate as the clinical method in analyzing nuclear cataracts.

In summary, the Pentacam Scheimpflug device offers an objective measure of nuclear lens density on nuclear cataracts. A comparative analysis between both Pentacam methods of lens density measurements (PLDP and PNS mean value) and LOCS III showed a positive correlation in groups 1 to 5 . Nevertheless, slight nuclear opalescence changes in the nuclear cataracts might not reflect in densitometric differences since statistical difference was not found in all groups. The Pentacam new software, PNS, gives us additional information about lens densitometry, especially considering its mean values, and might be useful to evaluate cataract progression in clinical practice. The PNS cataract grading score demonstrated, though, greater interpretation variability among the LOCS III groups.

\section{REFERENCES}

1. Chang MA, Congdon NG, Baker SK, Bloem MW, Savage H, Sommer A. The surgical management of cataract: barriers, best practices and outcomes. Int Ophthalmol. 2008;28(4): 247-60.

2. Leske MC, Wu SY, Nemesure B, Li X, Hennis A, Connell AM. Incidence and progression of lens opacities in the Barbados Eye Studies. Ophthalmology. 2000;107(7):1267-73.

3. Davison JA, Chylack LT. Clinical application of the lens opacities classification system III in the performance of phacoemulsification. J Cataract Refract Surg. 2003;29(1):138-45.

4. Chylack LT Jr, Wolfe JK, Singer DM, Leske MC, Bullimore MA, Bailey IL, et al. The Lens Opacities Classification System III. The Longitudinal Study of Cataract Study Group. Arch Ophthalmol. 1993;111(6):831-6.

5. Tan AC, Loon SC, Choi H, Thean L. Lens Opacities Classification System III: cataract grading variability between junior and senior staff at a Singapore hospital. J Cataract Refract Surg. 2008;34(11):1948-52

6. Wolffsohn JS, Davies LN. Advances in anterior segment imaging. Curr Opin Ophthalmol. 2007;18(1):32-8

7. Al-Mezaine HS, Al-Amro SA, Kangave D, Sadaawy A, Wehaib TA, Al-Obeidan S. Comparison between central corneal thickness measurements by oculus pentacam and ultrasonic pachymetry. Int Ophthalmol. 2008;28(5):333-8.

8. Rabsilber TM, Khoramnia R, Auffarth GU. Anterior chamber measurements using Pentacam rotating Scheimpflug camera. J Cataract Refract Surg. 2006;32(3):456-9.

9. Swartz T, Marten L, Wang M. Measuring the cornea: the latest developments in corneal topography. Curr Opin Ophthalmol. 2007;18(4):325-33.

10. Pei X, Bao Y, Chen Y, Li X. Correlation of lens density measured using the Pentacam Scheimpflug system with the Lens Opacities Classification System III grading score and visual acuity in age-related nuclear cataract. Br J Ophthalmol. 2008;92(11):1471-5.

11. Chylack LT Jr, Wolfe JK, Friend J, Tung W, Singer DM, Brown NP, et al. Validation of methods for the assessment of cataract progression in the Roche European-American Anticataract Trial (REACT). Ophthalmic Epidemiol. 1995;2(2):59-75. Comment in: Ophthalmic Epidemiol. 1996:3(2):59-60.

12. Uçakhan OO, Gesolu P, Ozkan M, Kanpolat A. Corneal elevation and thickness in relation to the refractive status measured with the Pentacam Scheimpflug system. J Cataract Refract Surg. 2008;34(11):1900-5.

13. Datiles MB $3^{\text {rd }}$, Magno BV, Freidlin V. Study of nuclear cataract progression using the National Eye Institute Scheimpflug system. Br J Ophthalmol. 1995;79(6):527-34

14. Sasaki K, Fujisawa K, Sakamoto Y. Quantitative evaluation of nuclear cataract using image analysis. Ophthalmic Res. 1992;24 Suppl 1:26-31. 